\title{
Dever de casa:visões de mães e professoras ${ }^{1}$
}

\section{Homework: mothers' and teachers' views ${ }^{2}$}

\author{
Maria Eulina Pessoa de CARVALHO* \\ Marta Helena Burity SERPA**
}

\begin{abstract}
Resumo: Diante de sua importância no cotidiano das relações família-escola, o dever de casa tem sido pouco pesquisado em suas concepções, práticas e implicações, seja para a vida familiar, seja para o trabalho docente. A ênfase em sua adoção vem crescendo no atual contexto de política educacional neoliberal de incentivo à participação dos pais na escola e de avaliação da produtividade escolar. Este trabalho é uma análise preliminar de dados de investigação sobre concepções e práticas de dever de casa envolvendo entrevistas com mães e professoras de alunos e alunas de escolas públicas e privadas ensino fundamental de Campina Grande/PB, João Pessoa e municípios vizinhos. Os dados revelam as dificuldades e visões ambíguas acerca do dever de casa das mães de baixa renda e escolaridade, cujos filhos e filhas freqüentam as escolas públicas. Indicam que nas famílias com menos recursos materiais e culturais, o clima do dever de casa é de maior sofrimento e conflito para mães, filhos e filhas, evidenciando-se a problemática da relação entre o dever de casa e as dificuldades escolares dos estudantes, particularmente quando se considera que as professoras esperam a adesão da família ao dever e que sua feitura ou não afeta a avaliação e as chances de sucesso ou fracasso escolar.
\end{abstract}

Palavras-chave: dever de casa. relações família-escola.

Abstract: Emphasis on the adoption of homework has been growing within present neoliberal educational policies, including assessment of school productivity and incentives to parental participation in schooling. However, considering its importance for family and school relations, homework has been insufficiently researched regarding

\footnotetext{
${ }^{1}$ Trabalho apresentado na 28a Reunião Anual da ANPED, GT Sociologia da Educação, Caxambu, 16 a 19 de outubro de 2005.

${ }^{2}$ Study presented at the ANPED 28th Annual Meeting, Study Group Sociology and Education, Caxambu, 16th to 19th October 2005.

* Doutora em Currículo, Ensino e Política Educacional pela Michigan State University, USA. Professora do Departamento de Habilitações Pedagógicas, Centro de Educação, Universidade Federal da Paraíba. E-mail: mepcarv@terra.com.br

** Graduada em Psicologia pelos Institutos Paraibanos de Educação. Mestre em Psicologia (Psicologia Social) pela Universidade Federal da Paraíba. Professora Assistente da Universidade Federal de Campina Grande. E-mail: martaburity@ig.com.br
}

$$
\text { Olhar de professor, Ponta Grossa, 9(1): 31-46, } 2006 .
$$


conceptions, practices and implications, either for family life or teachers' work. This paper presents a brief analysis of research data on homework conceptions and practices obtained from interviews with mothers and teachers of $3^{\text {rd }}$ and $4^{\text {th }}$ grade students of public and private schools in Campina Grande, João Pessoa and other towns in the state of Paraiba, Brazil. Data reveal the difficulties and ambiguous views about homework of mothers of low income and little education, whose children attend public schools. They also indicate that the climate of homework time involves more suffering and conflicts for mothers and children with less material and cultural resources. The problematic relationship between homework and students' difficulties in schooling becomes evident, particularly when teachers expect parental support and when homework compliance affects students' evaluation and chances of school success or failure.

Keywords: homework. family and school relations.

\section{APROBLEMÁTICADODEVERDE CASA}

Como estratégia pedagógica tradicional, o dever de casa tem múltiplas finalidades: estender o tempo de aprendizagem, completar a quantidade de matéria que a professora deve cobrir, conectar o trabalho de classe precedente e subseqüente, estimular hábitos de estudo independente, aplicar os conhecimentos acadêmicos à vida cotidiana, enriquecer o currículo ampliando as experiências de aprendizagem, e conectar escola e família. Consistindo basicamente de exercícios de revisão, fixação e reforço, representa um recurso importante que potencialmente poderia beneficiar todos os estudantes, bem como aqueles que têm dificuldades (fazendo mais dever de casa) e aqueles que necessitam desenvolver certas habilidades (fazendo deveres de casa especiais). Constitui, então, uma concepção curricular e didática que articula o trabalho escolar (a aprendizagem acadêmica) em classe e em casa, e se integra ao processo de avaliação(CARVALHO, 2001).

Considerado por pais e professores como uma necessidade educacional, um componente importante do processo ensino-aprendizagem e do currículo escolar e uma ocupação adequada para os estudantes em casa, o dever de casa é idealizado como contexto de investimentos educativos dos pais em favor da escolaridade dos filhos, bem como de trocas afetivas entre pais e filhos. Por conseguinte, constitui uma política, tanto da escola e do sistema de ensino, objetivando ampliar e intensificar a aprendizagem em quantidade e qualidade, além do tempo/espaço escolar, quanto da família, visando estimular o progresso educacional e sócio-econômico dos descendentes (CARVALHO, 2004b). As famílias, inclusive das camadas populares, percebem a importância da incorporação do capital escolar e investem em estratégias educativas (ROMANELLI, 2003), entre as quais teria lugar de destaque o reforço es-

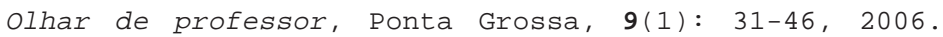


colar cotidiano representado pela adesão à prática do dever de casa.

Ora, desde a década de 1990 a política educacional neoliberal vem incentivando a participação dos pais na escola, com ênfase no acompanhamento ao dever de casa. A lógica de elevação da produtividade escolar, no contexto mundial de competitividade econômica, baseia-se na valorização do capital escolar para o desenvolvimento social e a empregabilidade; a avaliação educacional, de forte ênfase quantitativa, via testes padronizados aplicados em massa, permite comparações de desempenho, inclusive internacionais. Intensifica-se, assim, a mobilização em torno do dever de casa, típica das classes médias.

Nos EEUU, por exemplo, o New York Times (18/4/2004) estampou a manchete: Dever de casa aumenta em resposta a exigências curriculares e pressões de escolas de elite, enfocando a carga de deveres de casa de estudantes de $1^{\mathrm{a}}$ a $8^{\mathrm{a}}$ séries e a pressão sobre os pais/mães. O artigo explica que os padrões de avaliação na escola pública se elevaram e os testes requerem mais conteúdos do que a escola está conseguindo cobrir, mesmo antecipando programas, por exemplo, trabalhando na $6^{\mathrm{a}}$ série conteúdos de matemática que antes eram dados na $7^{\mathrm{a}}$ série. Sob pressão dos testes e da avaliação de estudantes e escolas, a política do Governo Bush denominada No Child Behind vem ameaçando de fechamento as escolas improdutivas a solução, para diretores/as e edu- cadores/as, tem sido aumentar o dever de casa, que está sendo adotado até no jardim de infância, para acostumar as crianças. Os pais e mães queixamse de que os deveres de casa aumentam o stress familiar, competem com as atividades extra-curriculares, atrapalham fins de semana, férias, refeições em família e horas de sono, descanso e lazer, aumentando os conflitos entre pais/mães e filhos/as, e pais/mães e educadores/as; por outro lado, estão apelando para professores particulares e Clubes de Dever de Casa, já que são poucas as escolas que oferecem assistência antes ou após as aulas. Uma novidade é que empresas privadas estão prosperando em comunidades de classe média alta oferecendo apoio ao dever de casa não apenas a estudantes com dificuldades, mas a estudantes excelentes que querem manter o nível de aproveitamento (ROSENBERG, 2004). A assistência educacional simultaneamente aos pais/ mães e estudantes das escolas públicas, um novo negócio privado, vem sendo oferecida também via tecnologias da informação e comunicação.

Esse quadro lembra a experiência escolar das camadas médias brasileiras, cujos filhos freqüentam escolas particulares e contam com diversas estratégias de investimento em seu sucesso escolar, com acompanhamento em casa e na escola, conforme demonstrado por Nogueira (1998) e Franco (2002). A importância do dever de casa, cultivada desde a pré-escola no 
âmbito da educação privada, já aparece na internet, onde escolas publicam sua política e resultados do dever de casa em sítios eletrônicos.

Nesse contexto, a tradição cultural e pedagógica do dever de casa tende a se formalizar em política educacional de incentivo à participação dos pais também na escola pública. O MEC instituiu o Dia Nacional da Família na Escola e publicou, em 2002, a cartilha Educar é uma tarefa de todos nós. Um guia para a família participar, no diaa-dia, da educação de nossas crianças (Brasil, 2002), com base em análises dos resultados do SAEB que destacam "o hábito de fazer a lição de casa no rendimento do aluno" (BRASIL, 2003). Recentemente, a Folha de São Paulo (27/07/2004) estampou a manchete Acompanhamento familiar eleva nota dos alunos, com base na análise, feita pelo INEP, dos resultados do cruzamento das notas de língua portuguesa e matemática com as respostas do questionário socioeconômico do SAEB 2003, aplicado a uma amostra de 300 mil estudantes, da $4^{\mathrm{a}}$ e $8^{\mathrm{a}}$ séries do ensino fundamental e $3^{\mathrm{a}}$ série do ensino médio, das redes pública e privada, enfocando especificamente se os pais ou responsáveis conversam sobre o que acontece na escola e cobram a lição de casa (FOLHA ONLINE EDUCAÇÃO, 2004a).

Pouco depois (1/8/2004), no mesmo jornal, outra manchete - Escola pública boa deve começar em casa - anuncia artigo que reproduz a mesma retórica empregada nos EUA: "A receita para uma boa escola pública é simples e dá resultados. Seus principais ingredientes são a participação dos pais, o interesse da família pela vida escolar do aluno, o estímulo à leitura e o hábito de fazer e corrigir o dever de casa" (FOLHA ONLINE EDUCAÇÃO, 2004b). Tal retórica se baseia em pesquisa com alunos de escolas públicas de São Paulo e Santa Catarina, integrantes do projeto Gestão para o Sucesso Escolar, que constatou que os alunos da $4^{\mathrm{a}}$ série que obtêm mais acertos nas provas são aqueles cujos pais perguntam se estão indo bem na escola e participam de reuniões da escola. A coordenadora da pesquisa ressalta: "O hábito de fazer dever de casa é uma das variáveis que mais têm impacto positivo", evidenciando a importância da sua cobrança pelos professores, e "mesmo pais com pouca escolaridade podem ajudar os filhos a ter boas notas se demonstram interesse pela vida escolar da criança e participam das atividades do colégio" (FOLHA ONLINE EDUCAÇÃO, 2004b). A mesma ênfase nas conversas domésticas sobre o desempenho escolar, no incentivo ao estudo em casa e na demanda do dever de casa, "que qualquer pai pode fazer", aparece no Decálogo dos Pais proposto por Castro (Revista VEJA, 16/03/2005).

$\mathrm{O}$ fato importante é que o dever de casa repercute direta ou indiretamente na avaliação: vale nota ou pontos somados à nota final, ou serve como treino para os testes. Por isso, tem sido considerado uma panacéia para melho- 
rar o aproveitamento escolar e constitui uma questão política com graves implicações para um projeto de equidade da educação escolar (CARVALHO, 2001). Como argumenta CAR$\operatorname{VALHO}(2004 a, 2004 b, 2000)$, a política de envolvimento dos pais na escola via dever de casa tem implicações de classe e gênero ${ }^{3}$ : quando a escola requer a contribuição acadêmica da família, pressupõe um modelo de família com capital econômico, cultural e escolar, geralmente com uma mãe disponível e uma estrutura doméstica de apoio às atividades escolares. Os formuladores de política educacional não consideram a relação entre modelos de organização curricular e pedagógica e modelos de organização familiar, as mudanças e variações nos arranjos familiares, nem a assimetria nas relações de gênero que atribui a responsabilidade pelos/as filhos/as às mulheres. David (1989) há muito argumentou que as relações família-escola, assim como as noções de família, lar, pais/mães e responsabilidade parental são gendradas. Diante do aumento de famílias monoparentais chefiadas por mulheres, as implicações familiares e de gênero do dever de casa devem ser ressaltadas: da perspectiva da família, o dever de casa pode ser uma prática desejável ou um fardo, dependendo de condições materiais e simbólicas variáveis; ademais, pesquisas constatam que o dever de casa tem recaído sobre as mães (FRANCO, 2002; CARVALHO, 2004a).

Assim, ao desviar o foco da melhoria educacional da escola/sala de aula para a família/lar, a política educacional neoliberal produz efeitos perversos: restringe a autonomia da família na auto-regulação da vida de seus membros, na organização de suas atividades/tempos/espaços e na condução da educação doméstica, e converte diferenças de capital econômico, cultural e social (Bourdieu, 1986) em resultados educacionais desiguais. Em relação à vida familiar, tal política cria tensões ao impor a concepção de que o lar deve ser um local para o desenvolvimento do currículo escolar, privilegiando um modelo único de família e papel parental, desconhecendo as diferenças entre os grupos sociais que se traduzem em vantagem ou desvantagem escolar (Lareau, 1993). Conseqüentemente, reforça a desigualdade de aprendizagem, fazendo a avaliação do estudante corresponder à avaliação do desempenho das mães, e limita a liberdade da família de escolher seu estilo de vida e currículo doméstico/ informal sem que seus filhos/as sejam penalizados no contexto competitivo da avaliação escolar (CARVALHO, 2001, 1998). O viés etnocêntrico e

\footnotetext{
${ }^{3}$ Paro (2000) omite as estruturas de classe e classe e gênero em sua pesquisa sobre a contribuição dos pais para a qualidade do ensino na escola pública. Castro (In Revista VEJA, 2005) talvez tenha se dirigido aos pais-homens, mas não considera diferenças de capital econômico e simbólico.
} 
classista, que toma como referência o modelo de família nuclear (biparental) das camadas médias (ROMANELLI, 2003), reforça a culpa pelo fracasso escolar das famílias que nele não se enquadram.

Diante de sua importância no cotidiano das relações família-escola, o dever de casa tem sido pouco pesquisado. Embora seja uma prática cultural que há muito integra a divisão de trabalho educacional entre essas instituições, não tem sido devidamente problematizado em suas concepções, práticas e implicações, seja para a vida familiar, seja para o trabalho docente. Uma questão crítica é: em que medida, a que custo e para quem é o dever de casa eficaz?

\section{CONTEXTOS DE PESQUISA}

Este texto apresenta uma análise preliminar de dados de investigação sobre concepções e práticas de dever de casa desenvolvida em dois contextos.

O primeiro contexto é um projeto integrante do Programa de Iniciação a Docência-PROLICEN(BURITY, 2004). Concebendo a investigação científica como parte fundamental da formação profissional, o projeto enfoca a problemática do dever de casa ${ }^{4}$, um assunto ausente da formação docente inicial. As bolsistas ${ }^{5}$ foram orientadas na realização de entrevistas com professoras, mães e estudantes de $3^{\mathrm{a}}$ e $4^{\mathrm{a}}$ séries de escolas públicas e privadas de Campina Grande, a fim de subsidiar a reflexão sobre as escolhas (políticas) que orientam as práticas docentes e ampliar o contexto de reflexão sobre essas práticas. Realizadas no segundo semestre de 2004, as entrevistas versaram sobre os seguintes aspectos: concepções sobre o dever de casa, atribuição de responsabilidade (professora/pais/estudante), quantidade e qualidade da adesão ao dever, quem acompanha em casa, se a criança gosta ou não, se faz, preferências, rejeição, clima no momento da realização, reações da professora, elaboração e correção (método e tempo), como integra a avaliação (pontos/nota), se representa um ônus para o estudante/família, problemas e sugestões.

O estudo descritivo-qualitativo envolveu três escolas estaduais e três municipais, com clientela de camada sócio-econômica inferior, e quatro

\footnotetext{
${ }^{4}$ Objetiva verificar e analisar as concepções e práticas de professoras do ensino fundamental sobre o tradicional dever de casa e propor alternativas pedagógicas que substituam essas tarefas domiciliares por atividades que possam eliminar barreiras à aprendizagem; verificar e analisar as dificuldades dos estudantes na sua realização, considerando a hipótese de contribuírem para o fracasso escolar; identificar junto aos pais/mães os pontos em que os deveres de casa dificultam a prática do paradigma da educação para todos, visto que as famílias atendidas pelas escolas públicas possuem poucos recursos materiais e culturais para corresponderem às expectativas escolares.

${ }^{5}$ Agradecemos a Mayra L. Batista e Daniely A. de Medeiros, alunas de Pedagogia, UFCG.
} 
escolas privadas de porte médio ou grande, localizadas no centro (para excluir escolinhas privadas de periferia), com clientela de classe média. A escolha das escolas se deu pela facilidade de acesso das bolsistas. Utilizou-se um roteiro de entrevista semiestruturada, abordando aspectos sócio-demográficos e a experiência do dever de casa. As 42 entrevistas gravadas incluem sujeitos ligados, isto é, a mesma mãe da mesma criança da mesma professora, sendo nove grupos de escolas públicas, e cinco de escolas privadas, 14 sujeitos de cada segmento. A primeira entrevista era realizada com a professora, que indicava o/a aluno/aluna e a mãe que, no seu julgamento, se disporiam a colaborar com a pesquisa; não foi possível entrevistar nenhum pai. Ocorreu resistência de mães de escolas privadas que alegaram falta de tempo, e de uma mãe analfabeta de escola pública. As entrevistas foram feitas em horários e locais preestabelecidos, na escola, em casa ou no local de trabalho da mãe, conforme disponibilidade dos sujeitos. Após a apresentação dos objetivos da pesquisa e esclarecimentos sobre o sigilo e o anonimato dos sujeitos, as entrevistas individuais foram gravadas, permitindo-se aos entrevistados falarem à vontade, sem tempo pré-estabelecido.

Esse desenho metodológico permite diversas possibilidades de análise horizontal e vertical: só das visões e práticas das professoras, idem dos/ das estudantes, idem das mães; comparações entre dois ou três segmentos; comparações entre segmentos por tipo de escola (pública/privada); e casos de grupos de sujeitos ligados quanto a concepções e práticas exemplares. Aqui se apresenta uma aproximação analítica inicial, destacando-se as visões e experiências das mães no contexto da relação mãe-estudante mediada pelo dever de casa.

O segundo contexto é uma experiência em aulas da disciplina Pesquisa em Educação, do Curso de Pedagogia da UFPB, desenvolvida desde 2003. Visando conhecer as visões e práticas de professoras do ensino fundamental, aproveita-se a disciplina para aplicar um questionário ${ }^{6}$ às alunas, a gran-

\footnotetext{
${ }^{6} \mathrm{O}$ dever de casa (DC) é uma prática amplamente adotada? Como é utilizado em diferentes escolas e séries? É uma política da escola? Por que é adotado, segundo as professoras? Qual seu objetivo e significado? É planejado individual/coletivamente? Recebe orientação da coordenadora pedagógica? Quais os tipos/frequência de DC utilizados? Qual a previsão de tempo diário para o DC? Como é corrigido? Integra a avaliação? Como? Vale nota? E quanto à adesão dos alunos? Fazem/gostam dos DCs? Quem são os alunos que faz em/não fazem? O DC é elaborado para o aluno fazer sozinho ou requer ajuda? Quem é que ajuda em casa? Os pais pedem/aprovam o DC? Reclamam? Os alunos aprendem mais com o DC? Por que? Como explicam os bons resultados? Os alunos poderiam aprender também sem DC? Como? No mesmo questionário indaga-se também sobre a experiência das respondentes como alunas no seu tempo de escola básica, e hoje como mães, caso tenham filhos/as.
}

$$
\text { Olhar de professor, Ponta Grossa, 9(1): 31-46, } 2006 .
$$


de maioria professoras do Programa Estudante Convênio Rede Pública (PEC-RP) que lecionam nas séries iniciais. Esse questionário serve a elas como exemplo/vivência de pesquisa.

Os dados indicam que a grande maioria adota dever de casa para fins de reforço e revisão, sendo os formatos mais freqüentes pesquisas, exercícios de fixação de português e matemática, leitura, produção de texto, desenho, pintura e colagem. As professoras acreditam que os estudantes aprendem mais com o dever de casa, que é corrigido predominantemente de forma coletiva e incluído na nota através de avaliação qualitativa, considerando responsabilidade e participação. A maioria dos alunos/as faz os deveres regularmente e os que não fazem são descritos como: bagunceiros, desinteressados, não gostam de estudar; com deficiências de aprendizagem; têm pais/mães ausentes, analfabetos; não têm ajuda em casa. Quase todas as professoras dizem elaborar os deveres com a preocupação de possibilitar que o aluno possa fazer sozinho, e que os pais aprovam o dever de casa (Carvalho, 2003).

Nem todas as professoras/alunas de Pedagogia respondem a todas as questões ou oferecem respostas detalhadas, o que demonstra os limites do questionário. No primeiro semestre de 2005, logo após sua aplicação, realizou-se um grupo focal com cinco professoras de escolas públicas, com tempo de magistério entre 5 e 25 anos, visando explorar melhor e discutir as questões. Tal abordagem revelou dados interessantes, sobretudo no caso de professoras que se posicionaram simultaneamente como mães. É esse o recorte apresentado adiante.

\section{MÃES DE ESCOLAS PÚBLICAS: DIFICULDADES E VISÕESAMBÍ- GUAS ACERCA DO DEVER DE CASA}

As nove mães de escola pública entrevistadas apresentam o seguinte perfil: idades entre 29 e 52 anos; número de filhos entre um e cinco; duas chefes de família; três analfabetas, duas com $2^{\circ}$ grau incompleto, três com $2^{\circ}$ grau completo e uma com curso superior; três donas de casa, três empregadas domésticas, uma manicure, uma auxiliar de serviços de escola municipal, e uma bibliotecária. Quanto a renda familiar, uma se situava abaixo do salário mínimo e era beneficiária do Programa Bolsa-Família, cinco se situavam entre 1-2 salários mínimos, duas entre 2-3 salários mínimos e uma entre 4-5 salários mínimos. Os quatro filhos e cinco filhas têm idades entre 8 e 13 anos; portanto, quatro crianças com idades acima da correspondente à série.

Foi difícil a comunicação com essas mães sobre os assuntos escolares e as questões da entrevista tiveram de ser repetidas, exceto nos casos da mãe com escolaridade superior e da funcionária da escola, que havia voltado a estudar e completado o ensino médio e dominava a linguagem 
pedagógica. Todavia, mesmo essas duas mães não tinham uma idéia precisa do papel do dever de casa na avaliação: sabiam que fazia parte da avaliação continua, mas ignoravam como integrava as notas.

Inicialmente, elas expressaram visões positivas sobre o dever de casa, considerando-o favorável tanto ao desenvolvimento acadêmico, por estender o tempo de aprendizagem, quanto ao desenvolvimento da responsabilidade e autonomia: "é mais uma ocupação para que as crianças venham se desenvolver melhor na escola"; "é um tempo de estudo a mais"; "a responsabilidade que a criança vai ter de fazer aquele dever"; "quando ela consegue fazer os dever sozinha ela se sente até orgulhosa". O dever de casa também é valorizado em oposição à brincadeira e à preguiça: "porque criança só pensa em brincar, não quer nada com a vida"; às vezes ela tem muita preguiça"; "ela é muito esquecida"; "ele acha bom quando não tem, porque fica descansando"; "quando chega em casa ela só quer saber de brincar"; "ele prefere assistir televisão"; "ele fica enrolando"; "ele é doido pra terminar pra sair pra rua".

Todas as mães manifestaram preocupação com a aprendizagem de seus filhos/as, e a noção de responsabilidade compartilhada entre família e escola. Definiram seu papel como estimular e aconselhar as crianças a estudar. Sua adesão ao dever de casa é gendrada: "eu que sou a mãe dela, é minha obrigação"; "eu que estou em casa é que procuro tirar as dúvidas dele"; "sou aquela mãe que sempre estou preocupada"; "sempre a realização das tarefas é comigo, que eu sou mais paciente". Apenas uma mencionou a ajuda do pai.

Há pesquisas indicando que os/as pais/mães desejam envolver-se com a vida escolar dos filhos/as e receber orientações específicas das professoras (Dauber \& Epstein, 1993; U.S. Department of Education, 1987). Contudo, tais descobertas são duvidosas com base no fato de que, quando questionadas diretamente e sendo implicitamente avaliadas como mães/pais, as pessoas tendem a confirmar as expectativas dos profissionais da escola, as idéias convencionais sobre boas mães/ bons pais, e as obrigações morais em relação ao sucesso escolar dos filhos/ as (Carvalho, 2001).

De fato, no início da entrevista as mães disseram, com maior ou menor ênfase, que o dever de casa não era um problema e que seus filhos ou filhas gostavam de fazê-lo. Porém, mais adiante, quando perguntadas sobre o clima durante a hora do dever de casa (como você se sente? como você acha que seu filho ou filha se sente?) os problemas surgiram. Embora parecessem aderir à expectativa de papel parental de ajuda ao dever de casa, revelaram dificuldades ou porque não sabiam ler, ou porque não tinham tempo, ou porque não sabiam ensinar, ou porque o que estudaram em seu tempo de escola era diferente de agora.

O dever de casa apareceu claramen- 
te como um fator de desgaste emocional para mães e filhos/as: "eu fico nervosa"; "ele/ela fica nervoso/a". Os termos usados para fazer referência à hora do dever de casa foram: aborrecimento, discórdia, medo, estressante, irritante, frustrante, "todo esse pelejar com ela para fazer o dever de casa". As crianças sentem-se forçadas, angustiadas, reclamam, resistem e choram porque não sabem fazer o dever. "Ele começa a chorar. Sempre se angustia com as tarefas". "Quando ela não consegue, chora e diz que não quer mais estudar".

As mães têm de pressionar as crianças para fazerem o dever: "Eu reclamo com ele. Só faz forçado". "Ele só faz quando eu fico cobrando mesmo". "Às vezes ele esconde". "Ela fica calada, num me fala nada, não". "Sempre estou ameaçando ele. Se você não fizer, eu vou saber da professora como é que tá indo". "Ela é muito teimosa". "Ele é uma criança muito desobediente". "Vai ficar de castigo". "Quando ela não quer fazer, é preciso uma punição mais severa para que ela faça".

Quatro mães então declaram que suas crianças não gostam de fazer o dever de casa: "Com certeza ela não gosta de fazer o dever de casa. Ela faz obrigada e chora. Um dia ela rasgou até a folha para não fazer". Três mães revelaram que têm de bater nas crianças para que façam o dever: "Tem vez que bato até nela, porque ela chora, porque não sabe fazer o dever de casa".

As crianças apelam para a ajuda de tias, vizinhas, irmãs ou irmãos mais velhos. Têm vergonha de pedir ajuda a vizinhas, nem sempre disponíveis. Um irmão não tem paciência; nem o pai, quando a mãe (a bibliotecária) precisa sair de casa e pede ajuda do marido: "Mainha, pelo amor de Deus, não deixe Painho me ajudar nas tarefas".

Ameaças e punições também vêm da escola: 'Oh, Mainha, se eu num fazer a tarefa, tia num vai deixar eu ficar no recreio". "Tia disse que não é para levar sem fazer o dever de casa, senão eu amanhã fico sem lanche".

Algumas mães apontam que são culpadas se os filhos/as não fazem os deveres: "A escola só culpa a mãe, nem adianta se a criança tiver pai". "A reação da professora é colocar a culpa em mim, e ela nem sabe por que eu não ensinei a tarefa para ela". "A professora disse: Sua mãe estava fazendo o quê? Por que não lhe ajudou na tarefa?"

No final da entrevista, algumas mães expressaram a expectativa de que a escola e a professora deveriam estimular as crianças a fazerem e gostarem do dever de casa. Além disso, permitiram-se dizer: "Se os professores não passassem tanto dever de casa, seria muito mais fácil". "Às vezes penso sozinha: seria tão bom se as professoras não mandassem tarefas de casa, porque imagine toda hora de tarefa de casa ser aquele barulho para poder a criança fazer o dever". "Às vezes eu acho que o dever de casa é sim um problema, porque os professores deveriam achar uma nova maneira sem passar tanto dever de casa". A mãe com 
escolaridade superior conjeturou: "Eu sei que tem mãe que trabalha o dia todo, às vezes o pai chega e o filho vai saindo pra escola, não vê nem o pai; nesse caso em que a família não tem condições de dar assistência eu acho o dever de casa um problema, e a solução seria a escola acabar com o dever de casa ou então colocar professores à disposição dos alunos nas horas vagas".

\section{MÃES DE ESCOLAS PRIVADAS: NEMTÃO ENVOLVIDASASSIM!}

As cinco mães de escolas privadas têm idades entre 30 e 46 anos; dois filhos; escolaridade do $2^{\circ}$ grau incompleto ao superior; renda familiar entre 7-8 salários mínimos; e todas trabalham fora, exceto uma. Seus dois filhos e três filhas encontram-se na idade correspondente à série: um com 9 anos na $3^{\mathrm{a}}$ e os demais com 10 anos na $4^{\mathrm{a}}$ série.

Essas mães não têm problemas com o dever de casa: as crianças fazem sozinhas, ou com ajuda delas e do pai, ou ainda da empregada. Em um caso, a mãe declarou que a filha faz com o pai, "porque ele tem mais tempo disponível do que eu (...) a parte de tarefa quem acompanha mesmo é ele". A visão geral é que "a escola só trabalha bem se for em conjunto com a família" e elas sabem que o dever de casa vale nota ou pontos a mais ou a menos na nota.

Todavia, o clima dos deveres de casa é também estressante, segundo quatro das mães, apesar de menos dramático do que nos relatos das mães de escolas públicas: "eu brigo com ele antes"; "quando ela não consegue é um tormento, ela azucrina o juízo de todo mundo, ela chora"; "eu mando ele fazer brigando, mas ajudando, ele omite, aí eu pego no pé dele e brigo, se torna estressante por causa disso"; "eu acho muita tarefa e se torna muito cansativo para ele”; “às vezes, ele não gosta muito quando é pergunta, questionário, exercício, a maioria das vezes ele reclama, por ser grande a quantidade, duas ou três folhas, sabe que tem que fazer porque é obrigação"; "ele esconde, aí quando eu vou descobrir, aí eu fico zangada"; "eu acho que pesa, muitas vezes é muito exercício, muito conteúdo que cansa ele, quando é muito ele faz de tarde e de noite, ele diz que não agüenta mais a cabeça"; "aqui em casa há discussão por conta desses deveres dele, é motivo de briga, eu acho que é excessivo"; "só que se torna cansativo para ela, muitas vezes quando ela termina tá com dor de cabeça, ela reclama da quantidade a ser feita no dia"; "algumas vezes eu fico com pena, diz que vai tirar zero, que não vai conseguir passar, que a tia vai tirar nota, ela se sente frustrada e incapaz"; "na maioria das vezes o meu esposo se estressa, ela termina a tarefa sozinha, devido ele ir se estressando com ela"; "isso sobrecarrega a gente e acaba prejudicando ela, com certeza pesa, no final ela não assimila mais nada, sobrecarregada"; "eles acabam tendo a imagem negativa do colégio,

Olhar de professor, Ponta Grossa, 9(1): 31-46, $2006 . \overline{41}$ 
acabam se sentindo tão cobrados"; "muitas vezes, por vir muita tarefa, eu não tenho paciência"; "eu procuro em livros, eu acho muito difícil, muita coisa assim difícil".

Essas mães alegam falta de tempo para se ocuparem com os deveres de casa dos filhos/as: "pra te falar a verdade eu não tenho tempo, não"; "mas quando eu não tenho tempo de ensinar, ela faz só"; "porque ela sempre faz mais sozinha, porque eu trabalho muito e só chego à noite em casa"; "o que vale é o tempo e isso é o que eu menos tenho"; "eu sou super ocupada, às vezes tenho tempo nos finais de semana"; "eu não posso ensinar a ele porque eu não tenho tempo e ele tem que fazer só". Também avaliam o dever de casa como um "exagero, porque até mesmo se a professora moderar vai ser mais interessante, as perguntas são muito difíceis e eu já vi por aí em outro colégio que é menos". E devolvem a responsabilidade de ensinar à escola: "se você não sabe J., mamãe não sabe também, então você leva pra escola e chega na escola você tira suas dúvidas com a professora"; "mas quando ela não sabe fazer sozinha, eu telefono pra professora lá da escola e ela me explica e ela faz"; "a responsabilidade maior seria da escola, é obrigação deles de ensinar e não nossa, não querer passar toda a responsabilidade em cima dos pais e dos alunos, quando a obrigação é deles"; "eu sinto que o professor passa a responsabilidade para os pais, porque poderia ser trabalhado mais na escola... a sugestão que eu te- ria é que eles administrassem melhor o tempo que eles usufruem no colégio".

\section{MÃE E PROFESSORA: DIFICUL- DADES COMUNS}

O grupo focal com sete professoras, estudantes do Curso de Pedagogia, com idades entre 31 e 49 anos, revelou uma concepção comum sobre o dever de casa como exercício de revisão e reforço dos conteúdos trabalhados em aula, que permite à professora avaliar a aprendizagem dos alunos e a participação dos pais - embora reconheçam que a ajuda em casa na maior parte das vezes é da mãe. Nas palavras de uma delas: "Serve também como justificativa para os pais, pois eles acham que estão acompanhando os conteúdos dados pelos professores".

Apenas em um caso, uma professora relatou que sua escola tem uma política de dever de casa, ou seja, esse é assunto das reuniões de planejamento e a supervisora orienta explicitamente que seja passado em pequena quantidade e só como revisão/reforço da aula, para garantir que o/a aluno/a possa fazer sozinho/a, considerando a falta de ajuda em casa. Os limites domésticos em meios pobres acarretam restrições ao tipo de tarefa: "Colagem eu nem passo mais, porque eles não têm revista nem cola em casa. Já recebi tarefas coladas com arroz, macarrão, esmalte e sabão".

Outra professora posicionou-se assim: "Essa questão do dever é problemática na escola pública; se a gen- 
te passa, acarreta até que as crianças apanhem em casa porque ficam aperreando a mãe que não tem condições de orientar". Contou um caso de um aluno que chegou com o caderno rasgado na aula e no outro dia a mãe veio se desculpar, "que passou a noite com outro filho no hospital e quando chegou em casa de manhã, o menino ficou aperreando pra ela ajudar no dever. Desesperada, rasgou o caderno e bateu nele". A professora refletiu: "Eu não condenei essa mãe, porque no lugar dela eu poderia ter feito a mesma coisa".

E continuou: "Dever pra nota eu já nem passo mais. Outro dia chegou uma mãe com uma menina chorando porque não tinha feito o dever que valia nota. Trabalho em uma escola pública na favela Boa Esperança e os alunos dessa escola são filhos de pais analfabetos, semi-analfabetos e menos da metade tem o ensino fundamental completo. As mães se queixam de não poder ensinar os exercícios dos filhos por falta de tempo."

Acumulando dois turnos de trabalho mais a freqüência à universidade, esta professora, divorciada, com um filho de dez e uma filha de seis anos, é sensível ao drama das mães de seus alunos: "Como mãe de alunos de escola privada também tenho vivenciado esse problema dentro de minha casa. Apesar de dispor de material necessário para as pesquisas, não tenho tempo de ajudar meus filhos nas suas tarefas e a professora já me chamou. Reclamei da quantidade de tarefas. A professora propôs mandar as tarefas atrasadas e acumuladas da semana no fim de semana. Protestei: no final de semana a criança deve estar livre de qualquer atividade escolar. Algumas vezes vejo mais quantidade do que qualidade. Por exemplo, escrever de 1 a 1000, isso é um castigo de casa para uma criança de $2^{\text {a }}, 3^{\text {a }}$ série".

Indagada sobre se ela estaria disponível para ensinar as tarefas no final de semana, acrescentou: "No sábado tenho meus trabalhos de faculdade para fazer, além do trabalho doméstico".

\section{CONCLUSÃO}

Em pesquisa sobre práticas familiares em relação ao dever de casa no contexto de camadas médias e escolas particulares de Belo Horizonte, Franco (2002, p.27) assinala:

Fazer deveres de casa exige tempo e esforço diários dos alunos e, em alguns casos, de seus familiares. Em muitas situações, restringem-se horários de lazer e de convívio social em função da realização dessa tarefa. Ainda como agravante, o não-cumprimento do trabalho escolar desencadeia atitudes punitivas tanto do professor como dos pais. Não fazer dever envolve sanções que variam de escola para escola, de professor para professor, de família para família.

É marcante a diferença nas condições para a prática do dever de casa entre grupos sociais de baixa renda e escolaridade da escola pública e gru- 
pos de classe média de escolas privadas, ressalvando-se a diversidade das famílias das camadas populares e médias (Romanelli, 2003) e de políticas/ práticas escolares. Os dados apresentados sugerem que algumas famílias e mães são mais vulneráveis e que, entre aquelas com menos recursos materiais e culturais, o clima do dever de casa é de maior sofrimento.

O dever de casa tanto é concebido como uma atividade que requer supervisão dos pais, quanto como uma tarefa que deve ser realizada com autonomia pelo estudante. As professoras se frustram quando a criança não traz o dever de casa feito e reclamam da falta de cooperação das mães, que se frustram quando seu filho ou filha não sabe fazer o dever e elas não têm tempo ou conhecimento para ajudar. Pensam que a criança não aprendeu porque não prestou atenção à aula ou que a professora não ensinou direito ou passou deveres inadequados. Mães com parco capital cultural e escolar não estão aptas a avaliarem a adequação pedagógica dos deveres de casa; assim, ou convivem com o conflito entre se culparem e culparem o/a filho/a, ou se desligam.

Portanto, é nas camadas mais pobres que estão na escola pública que se evidencia a problemática da relação entre o dever de casa e as dificuldades escolares dos/as estudantes, particularmente quando se considera que as professoras esperam a adesão da família/mãe ao dever de casa, e que sua feitura ou não afeta a avaliação e as chances de sucesso ou fracasso escolar. Os dados apresentados sugerem que o remédio (dever de casa) pode estar funcionado como veneno para algumas crianças, mães e lares.

Ora, a suposta eficácia do dever de casa depende não apenas da contribuição da família, mas sobretudo do planejamento pedagógico empreendido pela professora. Rebelo e Correia (1999) apontam a relatividade da eficácia do apoio familiar no desempenho escolar dos alunos e são críticos quanto aos efeitos negativos do dever de casa na motivação do/a aluno/a, na relação aluno/a-escola, na relação aluno/a-família, e na relação família-escola, que podem resultar em impaciência, hostilidade e conflitos abertos em qualquer desses âmbitos. Perrenoud (1995) também apresenta uma visão crítica das concepções/ práticas tradicionais do dever de casa e de suas repercussões negativas no clima das famílias. As solicitações escolares aos pais/mães tendem a “enervá-los, culpabilizá-los, deixarlhes campo livre às angútias, transformá-los em explicadores, envenenar os serões familiares, e colocar os pais em situação de incompetência ou impotência" (p.152). Na contramão da atual política educacional neoliberal, propõe uma outra noção de tempo de trabalho em casa (TTC), caracterizado pela diferenciação, flexibilidade e "utilizado em função das necessidades e dos projetos, não de forma regulamentada ou ritual" (p. 154). Adverte que o TTC não é feito 
para os pais, que estes não são os responsáveis pelo trabalho que os filhos têm de fazer em casa e que o TTC não deve ser objeto de avaliação formal.

\section{REFERÊNCIAS}

BOURDIEU, P. The forms of capital. In: RICHARDSON, J. G. (Ed.). Handbook of theory and research for the sociology of education. New York: Greenwood Press, 1986. p. 241-258.

BRASIL. Ministério da Educação e Cultura. Instituto Nacional de Estudos e Pesquisas Educacionais Anísio Teixeira. Notícias do SAEB. Brasília: Sala de Imprensa, 2003. Disponível em: $<$ http://www.inep.gov.br $>$ Acesso em: 13 dez. 2004.

BRASIL. Secretaria de Ensino Fundamental. Assessoria Nacional do Programa Parâmetros em Ação MEC/SEF. Educar é uma tarefa de todos nós: um guia para a família participar, no dia-a-dia, da educação de nossas crianças. Brasília/DF: MEC, 2002.

BURITY, M. H. Concepções do dever de casa na escola pública: implicações no fracasso escolar: Projeto PROLICEN. Campina Grande: Universidade Federal de Campina Grande; Departamento de Educação, 2004.

CARVALHO, M. E. P. Modos de educação, gênero e relações escola-família. Cadernos de Pesquisa, São Paulo, v. 34, p. 41-58, 2004a.

. Escola como extensão da família ou família como extensão da escola? O dever de casa e as relações família-escola. Revista Brasileira de Educação, n. 25, p. 94-104, jan./abr. 2004 b.

Dever de casa: práticas atuais e visões de professoras, estudantes de pe-

$$
\text { olhar de professor, Ponta }
$$

dagogia e mães. João Pessoa: UFPB; Centro de Educação, 2003.

Family-school relations: a critique of parental involvement in schooling. Mahwah, New Jersey, USA: Lawrence Erlbaum Associates, 2001.

Relações entre família e escola e suas implicações de gênero. Cadernos de Pesquisa. São Paulo, n. 110, p. 143-155, jul. 2000.

. A família enquanto objeto de política educacional: crítica ao modelo americano de envolvimento dos pais na escola. In: REUNIÃO ANUAL DA ANPED, GT Estado e Política Educacional, 21., 1998, Caxambu, MG. Anais eletrônicos... Caxambu, MG, 1998. Disponível em: $<$ http://www.anped.org.br $>$. Acesso em: 13 dez. 2004.

DAUBER, S.; EPSTEIN, J. Parent attitudes and practices of involvement in inner-city elementary and middle schools. In: CHAVKIN, N. F. (Ed.). Families and schools in a pluralistic society. Albany: State University of New York Press, 1993, p. 53-71.

DAVID, M. E. Schooling and the family. In: GIROUX, H. A.; McLAREN, P. (Ed.). Critical pedagogy, the state, and cultural struggle. Albany: State University of New York Press, 1989, p. 50-65.

ACOMPANHAMENTO familiar eleva nota dos alunos. Folha Online Educação. 2004a. Disponível em: <http:// wwwl.folha.uol.com.br/folha/educacao>. Acesso em: 27 jul. 2004.

ESCOLA pública boa deve começar em casa. Folha Online Educação. 2004b. Disponível em: <http:// www1.folha.uol.com.br/folha/educacao $>$. Acesso em: 01 ago. 2004

FRANCO, M. O. C. de M. Práticas famiGrossa, 9(1): 31-46, 2006. 
liares em relação ao dever de casa: um estudo junto às camadas médias de Belo Horizonte. 2002. Dissertação (Mestrado em Educação) - Faculdade de Educação, Universidade Federal de Minas Gerais, Belo Horizonte, 2002.

LAREAU, A. Home advantage. London: The Falmer Press, 1993.

NOGUEIRA, M. A. A escolha do estabelecimento de ensino pelas famílias: a ação discreta da riqueza cultural. Revista Brasileira de Educação, n. 25, p. 42-56, jan./ abr. 1998.

PARO, V. H. Qualidade do ensino: a contribuição dos pais. São Paulo: Xamã, 2000.

PERRENOUD, P. Ofício de aluno e sentido do trabalho escolar. Porto, Portugal: Ed. Porto, 1995.

REBELO, J. A. da S.; CORREIA, O. N. de O. N. O sentido dos deveres para casa. Coimbra, Portugal: Gráfica de Coimbra, 1999.

CASTRO, C. de M. O decálogo dos pais: ponto de Vista. Revista VEJA, São Paulo, ano 38, n. 11, p. - ,16 mai. 2005.

ROMANELLI, G. Questões teóricas e metodológicas nas pesquisas sobre família e escola. In: ZAGO, N.; CARVALHO, M. P. de; VILELA, R. A. T. (Org.). Itinerários de Pesquisa: perspectivas qualitativas em sociologia da educação. Rio de Janeiro: DP\&A, 2003.

ROSENBERG, M. When homework takes over [On-line]. The New York Times. April 18. 2004. Disponível em: < http:// www.nytimes.com>. Acesso em: 18 abr. 2004.

U.S. DEPARTMENT OF EDUCATION. What works: research about teaching and learning. Washington, DC: Author, 1987.
Encaminhado em: 28/03/06

Aceito em: 15/04/06 